\title{
Diálogos de Psicologia e Educação: tecendo histórias ${ }^{1}$
}

\section{Rodrigo Lopes Miranda*}

Universidade Federal de Minas Gerais - UFMG, Belo Horizonte, MG, Brasil

VAGO, T. M.; INÁCIO, M. S.; HAMDAM, J. C.; SANTOS, H. P. Intelectuais e escola pública no Brasil: séculos XIX e XX. Belo Horizonte: Mazza Edições, 2009. 181p.

O diálogo entre a psicologia e a educação no que se refere às suas histórias não se faz fortuito. Um dos campos em que a psicologia encontrou terreno fértil para seu desenvolvimento como ciência e profissão foi justamente a educação. Assim, é possível encontrar diversas fontes para a história da psicologia nos registros sobre a educação. $O$ inverso também é válido: podemos observar aspectos que expõem sobre a história da educação em documentos da psicologia. Isso não implica na redução de uma disciplina a outra, mas, sim, em observar novas possibilidades de diálogo, principalmente entre os campos da história da psicologia e da história da educação. Embora se situe como uma obra da história da educação, o livro Intelectuais e Escola Pública no Brasil: séculos XIX e $X X$ se encontra nessa interface, constituindo-se em uma ótima leitura para os interessados na história da psicologia.

O livro é um dos produtos do projeto interinstitucional "Pensar a Educação, Pensar o Brasil: 1822-2022". Os trabalhos apresentados na obra são produtos das conferências realizadas no âmbito desse projeto, no ano de 2007. Seus organizadores são Tarcísio Mauro Vago, Marcilaine Soares Inácio, Juliana Ceśario Hamdan e Hércules Pimenta dos Santos. Todos eles vêm desenvolvendo pesquisas e produzindo trabalhos em temáticas relativas à história da educação. O livro é subdividido em seis capítulos, antecedidos por um, de apresentação. Dentre os autores dos capítulos do livro, encontram-se pesquisadores de destaque, oriundos de diferentes universidades brasileiras, os quais apresentam diferentes abordagens historiográficas, promovendo diversas visões sobre a história da educação no Brasil.

$\mathrm{Na}$ apresentação do livro, nota-se um importante mote para as conferências realizadas em 2007 e a publicação da obra, em 2009. Seus organizadores sublinham o contemporâneo "entusiasmo pela educação", em face do "silêncio sobre a educação" pública. Nesse contexto, tornam-se recorrentes os discursos que levam a conceber os problemas educacionais brasileiros como "falta de educação 
escolar" ou "a falta de qualidade" das escolas. Diante desse quadro, a obra objetiva reapresentar a educação como "um objeto de reflexão da intelectualidade brasileira", estabelecendo critérios para uma crítica "ao novo entusiasmo da educação" e retomando "o lugar dos intelectuais da educação no debate público sobre educação no Brasil" (p. 7). Assim, o livro se coloca como uma possibilidade de reflexão sobre o papel que a educação assume na atualidade brasileira, a partir de investigações históricas sobre os papéis que lhe foram atribuídos nos dois últimos séculos. No processo de reflexão proposto pela obra, são colocados em destaque diversos agentes que se constituíram como intelectuais da educação brasileira. Dentre eles, José Bonifácio (1763-1838), Anísio Teixeira (1900-1971) e Fernando de Azevedo (1894-1974). A proposta geral da obra, bem como os agentes abordados nos capítulos, sugerem elementos para o diálogo entre a história da psicologia e a da educação. A maior parte do período trabalhado nos capítulos - início do século XIX e meados do século XX - coloca-se como um terreno fértil para se pensar tal diálogo, no Brasil. Isso porque é, nesse período, que as ideias psicológicas que se processavam no Brasil fortaleceram-se, sobretudo na interface com a Educação. Em 1890, a Reforma Benjamin Constant (Decreto no 981 , de 8 de novembro de $1890^{2}$ ) introduz conteúdos eminentemente psicológicos na formação de professores(as). Esse fortalecimento ainda se faz sensível, por exemplo, nas proposições de regulamentação da profissão e da formação do psicólogo, no Brasil (cf. Decreto no 21.173, de 19 de março de $1932^{3}$ e Lei no 4.119, de 27 de agosto de $1962^{4}$ ). Como a psicologia se constituía como ciência, pesquisando objetos e temas relacionados à educação, analisar a leitura das histórias da educação, no período, possibilita o contato com aspectos que se referem à psicologia brasileira, sobretudo se se observa a acentuação do discurso psicológico no Brasil, desde o fim do século XIX. Além disso, alguns dos atores abordados no livro, do mesmo modo, foram importantes para a psicologia, no Brasil, como, por exemplo, Anísio Teixeira, agente paradigmático do movimento escolanovista brasileiro. Esse autor, em 1934, apresenta diversos aspectos da psicologia para se pensar a educação brasileira, incluindo contribuições, desde a organização das disciplinas escolares, até teorias da aprendizagem (TEIXEIRA, 1934/2000). As possibilidades de diálogo entre a psicologia e a educação, observadas já de início, continuam no decorrer da obra.

O primeiro capítulo, intitulado "Os projetos de brasis e a questão da instrução no nascimento do império", de Luciano Mendes de Faria Filho, apresenta uma articulação entre projetos civilizatórios e questões educacionais no Brasil Império. O autor observa formas de inserção do Estado na seara da instrução elementar e a produção de leis como forma de ordenação do social, apresentando o "processo de 
escolarização [como] um dos elementos centrais na afirmação do Estado Imperial" (p. 19). Faria Filho discute, por exemplo, aspectos sobre as legislações e metodologias educacionais, noções da infância e propostas de formação de professores.

Algumas legislações educacionais vêm sendo objeto de trabalho na história da psicologia, principalmente a Reforma Benjamin Constant. Explorar as legislações que precedem a essa Reforma, por exemplo a Lei de 15 de outubro de $1827^{5}$, primeira lei brasileira que trata da instrução pública primária, como realizado por Faria Filho, pode fornecer novos elementos para analisar o desenvolvimento dos conteúdos psicológicos no Brasil, na interface com a educação. No que se refere aos métodos de ensino e à noção de infância, verificamse espaços frutíferos para observar os conteúdos psicológicos. Essas duas temáticas são terrenos em que a psicologia influenciou sobremaneira a educação, como vem sendo apontado por outros trabalhos (e.g. WARDE, 2006). Nessa direção, no texto de Faria Filho, notam-se passagens de potencial diálogo. Citando José Bonifácio, agente analisado pelo autor: "por meios destes (jogos ginásticos) se conseguirá que os pais folguem de ver seus filhos adiantados, e premiados, por suas boas ações e comportamento (...)" (p. 26). Nessa citação, verificam-se elementos que dizem de conteúdos eminentemente psicológicos, sobretudo a noção de comportamento. Assim, tanto as fontes quanto as temáticas trabalhadas pelo autor, permitem interlocuções com a história da psicologia. Possibilitam, especialmente, observar a questão dos conteúdos psicológicos nas "(...) estratégias civilizadoras da sociedade" (p. 37) brasileira.

O capítulo "Modernismos, modernidade e educação: o lugar dos intelectuais no Brasil dos anos 1930", de autoria de Diana Gonçalves Vidal, objetiva discutir o lugar dos intelectuais no debate sobre a educação no Brasil. A autora aborda a atuação de alguns intelectuais brasileiros ao longo dos anos de 1920 e 1930 e, também, observa as permanências contemporâneas dos debates produzidos nessas décadas. Os agentes destacados pela autora são Fernando de Azevedo e Anísio Teixeira. Em primeiro lugar, o recorte temporal estabelecido por Vidal já se torna atrativo. Segundo a autora, a década de 1920 foi preenchida por diversas iniciativas de intervenções sociais e, dentre elas, as educacionais. Essas iniciativas suscitaram "a elaboração de balanços, nos vários âmbitos sociais" que focavam a interpretação do passado e traçavam sentidos ao presente, mas "principalmente, traçavam rumos para o futuro" ( $p$. 122). Isso implicou na quantificação dos bens públicos e na avaliação dos bens culturais, como forma de "decifrar o país".

Nesse contexto, ocorre, por exemplo, a ascensão das escalas e dos testes psicológicos, como a criação do teste $A B C$ por Lourenço Filho. Assim, surge uma questão: será que o esforço estatístico de decifrar o Brasil, nas décadas de 1920 e 1930, influenciou a aceitação e a 
produção da psicometria pela psicologia brasileira? Igualmente, é entre essas décadas que se dá a publicação do Manifesto dos Pioneiros da Educação Nova, especificamente em 1932. Tal manifesto, segundo Vidal, "tramava um apagamento de práticas e educadores" (p. 125) do passado como forma de produção da alteridade do grupo de signatários desse documento. A delegação do passado ao esquecimento estava amparado pelo crivo científico, aspecto sublinhado pelos "pioneiros". Para eles, a psicologia situava-se entre as ciências de destaque. Curiosamente, é em 1932 que se publica o Decreto no 21.173, uma das primeiras iniciativas de regulamentação da profissão e da formação do psicólogo, no Brasil. Dessa maneira, o capítulo de Vidal apresenta fontes, agentes, elementos e recortes que podem ser utilizados para uma interpretação do período inicial da regulamentação da psicologia, no Brasil. Essa regulamentação se amparava nos fazeres psicológicos no ambiente educacional.

Além disso, a autora apresenta fontes pertinentes ao grupo dos "pioneiros da educação nova". Vários dos "pioneiros" apresentam relação direta com a psicologia e seu desenvolvimento no Brasil. Além do já citado Anísio Teixeira, Vidal trata sobre Fernando de Azevedo. Este ator, por exemplo, foi professor de psicologia no Ginásio Mineiro, na primeira década do século XX. Dessa maneira, observar leituras dos "pioneiros", relacionados à psicologia no Brasil, possibilita ampliar a leitura sobre a atuação desses intelectuais, tanto na educação, quanto na psicologia brasileira.

Os demais capítulos também apresentam temáticas, agentes e fontes que podem contribuir para interpretações da história da psicologia no Brasil. José Gonçalves Gondra, por exemplo, apresenta relações entre práticas higienistas e o caráter preventivo da educação escolar. $\mathrm{Na}$ psicologia, o higienismo é uma temática que, desde o fim da década de 1990, vem se apresentando como passível de análise por uma perspectiva historiográfica (e.g. ANTUNES, 1998/2007). Carlos Alberto Jamil Cury, por sua vez, identifica questões da centralidade da moral na legislação brasileira e na prática pedagógica, no fim do século XIX. A moral do professor e a formação moral da criança estavam em foco. Como se pode observar, essas temáticas possibilitam pensar a discussão sobre a moral frente ao crescente discurso científico que pretendia ordenar e racionalizar a experiência escolar. Como se sabe, nesses discursos, surgem conteúdos eminentemente psicológicos.

A partir da leitura da obra Intelectuais e Escola Pública no Brasil: séculos $X I X$ e $X X$, verificam-se diversas especificidades da produção da história da educação. O livro prima pela apresentação de diferentes perspectivas sobre a centralidade da educação nos discursos de civilizar e modernizar o Brasil, desde o Império. Além disso, apresenta os intelectuais como atores em determinados contextos de produção sem esbarrar no engodo da narrativa dos 
heróis e vencedores. Diante dessa leitura, verifica-se um conjunto de fontes, atores e temáticas que também dizem da história da psicologia no Brasil. Além disso, indica direções de diálogos entre a história da psicologia e a da educação, que marcam as especificidades de cada campo e as áreas fronteiriças para as interlocuções.

\section{Referências Bibliográficas}

ANTUNES, M. A. M. A psicologia em instituições médicas. In:

A psicologia no Brasil: leitura histórica sobre sua constituição. 5aed. São Paulo: Marco Editora e EDUC, 2007. p. 41-62. Original publicado em 1998.

CAMPOS, R. H. F. História da psicologia e história da educação conexões. In VEIGA, C. G. e FONSECA, T. N. L. (Orgs.). História e Historiografia da Educação no Brasil. 1.ed. e 1.reimp. Belo Horizonte: Autêntica, 2008. p. 129-158.

TEIXEIRA, A. Pequena introdução à filosofia da educação: escola progressiva ou a transformação da escola. 6.ed. Rio de Janeiro: DP\&A editora, 2000. Original publicado 1934. 173p.

WARDE, M. J. Para uma história disciplinar: psicologia, criança e pedagogia. In: FREITAS, M. C. (Org.). História Social da Infância no Brasil. 6.ed. São Paulo: Cortez, 2006. p.311-332.

\section{Endereço para correspondência}

Rodrigo Lopes Miranda

Av. Antônio Carlos, 6627, Faculdade de Educação, Universidade Federal de Minas Gerais, Pampulha, CEP 30270-901, Belo Horizonte - MG, Brasil.

Endereço eletrônico: dingoh@gmail.com

Recebido em: 27/01/2011

Aceito para publicação em: 31/01/2011

Acompanhamento do processo editorial: Ariane P. Ewald

\section{Notas}

* Mestre em Educação pelo Programa de Pós-graduação em Educação da Faculdade de Educação da Universidade Federal de Minas Gerais. Doutorando pelo mesmo Programa. Bolsista de doutorado CAPES.

${ }^{1} \mathrm{O}$ autor agradece às críticas e sugestões feitas por Luciano Mendes de Faria Filho e Sérgio Dias Cirino a versões iniciais deste trabalho. Todavia, quaisquer equívocos e imprecisões são de responsabilidade do autor.

${ }^{2}$ Disponível em:

<http://www.histedbr.fae.unicamp.br/navegando/fontes_escritas/4_1a_Republica/d ecreto\%20981-1890\%20reforma\%20benjamin\%20constant.htm>. Acesso em: 11 nov. 2010.

${ }^{3}$ Disponível em:

<http://www6.senado.gov.br/legislacao/ListaPublicacoes.action?id=34954>. Acesso em: 4 nov. 2010.

${ }^{4}$ Disponível em:

<http://www6.senado.gov.br/legislacao/ListaPublicacoes.action?id=113975>.

Acesso em: 4 nov. 2010. 
Rodrigo Lopes Miranda

Diálogos de Psicologia e Educação

${ }^{5}$ Disponível em: <https://www.meempi.com/heb05a.htm>. Acesso em: 11 nov. 2010. 